\title{
ChemComm
}

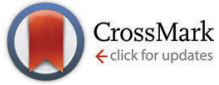

Cite this: Chem. Commun., 2015, 51, 9313

Received 29th March 2015, Accepted 29th April 2015

DOI: $10.1039 / \mathrm{c5cc02581h}$

www.rsc.org/chemcomm

\section{Solid lithium electrolytes based on an organic molecular porous solid $\dagger$}

\author{
Jun Heuk Park, ${ }^{\text {ab }}$ Kyungwon Suh, ${ }^{\text {ab }}$ Md. Rumum Rohman, ${ }^{a}$ Wooseup Hwang, ${ }^{\text {ab }}$ \\ Minyoung Yoon ${ }^{c d}$ and Kimoon Kim*abc
}

\begin{abstract}
A new type of solid lithium-ion conducting electrolytes prepared by incorporation of $\mathrm{Li}^{+}$ions into a cucurbit[6]uril (CB[6])-based organic molecular porous solid shows high $\mathrm{Li}^{+}$ion conductivity $\left(\sim 10^{-4} \mathrm{~S} \mathrm{~cm}^{-1}\right)$ and mobility (transference numbers, $t_{\mathrm{Li}}{ }^{+}=0.7-0.8$ ). In addition, the solid electrolytes show excellent, thermally stable performance even after several temperature cycles.
\end{abstract}

Lithium-ion batteries (LIB) hold great potential for application in powering electric vehicles and portable electric devices because of their high energy density, high (operating) voltage, and long duration compared to other rechargeable batteries. ${ }^{1,2}$ Over the last decade, significant progress has been made in the development of high energy density electrode materials. By contrast, no remarkable advancement was made in electrolyte materials, which play an important role in preventing direct contact between two electrodes and reversibly transporting ions to compensate for the system charge. Although widely-used liquid electrolytes have high ionic conductivity, their shortcomings such as restriction of battery shape, usage of flammable/ volatile electrolyte solvents and risk of their leakage limit their applications. ${ }^{3,4}$ Furthermore, a low $\mathrm{Li}^{+}$ion transference number (typically in the range of $0.2-0.5$ ), which results in a short cell lifetime, slow charging rate, and low energy density, has been another serious drawback of liquid electrolytes. ${ }^{5,6}$ To overcome the limitations, solid-type electrolyte materials such as ceramic and polymer type electrolytes have been studied extensively. ${ }^{7-10}$ Very recently, crystalline porous materials with well-defined pores

\footnotetext{
${ }^{a}$ Center for Self-assembly and Complexity, Institute for Basic Science (IBS), Pohang, 790-784, Republic of Korea

${ }^{b}$ Department of Chemistry, Pohang University of Science and Technology, 790-784, Republic of Korea.E-mail: kkim@postech.ac.kr

${ }^{c}$ Division of Advanced Materials Science, Pohang University of Science and Technology, 790-784, Republic of Korea

${ }^{d}$ Department of Nanochemistry, College of Bionano, Gachon University, Sungnam, 461-701, Republic of Korea

$\dagger$ Electronic supplementary information (ESI) available: Experimental details for preparation, characterization of materials and electrochemical measurement. See DOI: $10.1039 / \mathrm{c} 5 \mathrm{cc} 02581 \mathrm{~h}$
}

including metal-organic frameworks (MOFs) have been explored as $\mathrm{Li}^{+}$ion conducting materials, ${ }^{11-15}$ some of which showed good $\mathrm{Li}^{+}$ionic conductivity by grafting lithium precursors into open metal sites. However, low ionic conductivity, low cationic mobility, high interfacial resistance, and poor lithium compatibility of these solid-type electrolytes still hinder their practical applications. ${ }^{3,4,16}$ Thus, the design and fabrication of a safe, high-performing solid electrolyte material still remains a challenge.

Recently, we reported an organic molecular porous material (porous $\mathrm{CB}[6]$ ) made of cucurbit[6]uril, a pumpkin-shaped host molecule, which has a honeycomb-like structure with one-dimensional (1D) channels along the $c$-axis (average pore diameter $7.5 \AA$; pore aperture $6 \AA$ A). The porous $\mathrm{CB}[6]$ with permanent porosity and high thermal stability has been proved to be useful for a variety of applications including selective gas sorption and proton conduction. ${ }^{17-19}$ Especially, the porous $\mathrm{CB}[6]$ with 1D channels filled with water and acids showed both high and highly anisotropic proton conductivity, ${ }^{20}$ demonstrating that the 1D channels provide an excellent ion transport pathway. These previous findings and versatile properties of the porous $\mathrm{CB}[6]$ prompted us to investigate the $\mathrm{Li}^{+}$ion conduction in the 1D channels of the porous $\mathrm{CB}[6]$ matrix. Considering the confinement effect in the pores of a solid matrix, we thought that the intrinsic thermal runaway problem of liquid and the sudden decrease in conductivity at low temperature by crystallization, which is commonly observed in polymer matrices, ${ }^{21-23}$ can be avoided by using the porous $\mathrm{CB}[6]$ solid matrix. In addition, the crystalline porous $\mathrm{CB}[6]$ can be synthesized easily using common shelf reagents, and used without any tedious post-synthetic modification. We thus decided to incorporate the $\mathrm{Li}^{+}$electrolyte inside the channels to produce a safe and stable $\mathrm{Li}^{+}$ion conducting solid electrolyte.

Herein, we report a new type of solid lithium-ion conducting materials synthesized by incorporation of $\mathrm{Li}^{+}$ions into a cucurbit[6]uril (CB[6])-based organic molecular porous material (Scheme 1), which exhibits high $\mathrm{Li}^{+}$ion conductivity $\left(\sim 10^{-4} \mathrm{~S} \mathrm{~cm}^{-1}\right)$ and high cationic transference number $\left(t_{\mathrm{Li}}{ }^{+}=0.7-0.8\right)$. In addition, the solid electrolyte shows excellent, thermally stable performance 


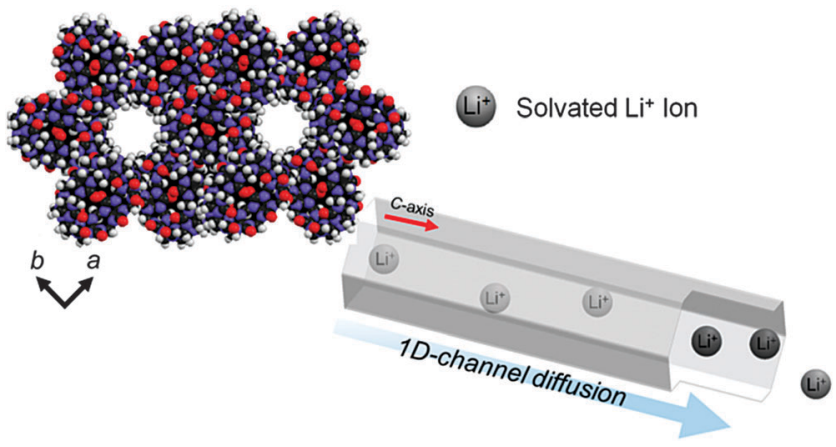

Scheme 1 Porous CB[6]-based solid lithium electrolyte showing a $\mathrm{Li}^{+}$ion transport pathway in the 1-D channels.

even after several temperature cycles. To the best of our knowledge, this is the first example of highly thermally stable, organic molecular porous material-based $\mathrm{Li}^{+}$ion conducting solid materials that simultaneously exhibit both high ionic conductivity and high cationic transference number.

Porous $\mathrm{CB}[6]$ (1) was prepared by recrystallization from aqueous $\mathrm{HCl}$ solution, following the previously reported procedure ${ }^{20}$ with some modifications. Solvent molecules filling the channels were removed by heating under a dynamic vacuum for the formation of guest free porous $\mathrm{CB}[6]$ (2), which was characterized using powder X-ray diffraction (PXRD), thermo-gravimetric analysis (TGA) and elemental analysis (EA) (see ESI $†$ ).

To introduce $\mathrm{Li}^{+}$ions into the channels of 2 , we chose propylene carbonate (PC) or dimethylcarbonate (DMC) as a solvent to dissolve lithium salts since they are widely used as solvents for $\mathrm{Li}^{+}$ion electrolytes due to high dielectric constant and solvating power (PC) or low viscosity and high lithium ion conductivity (DMC). We first tested and confirmed the excellent stability of 2 in the organic solvents using PXRD (Fig. S3, ESI $\dagger$ ). Soaking 2 in $1 \mathrm{M}$ solution of $\mathrm{LiPF}_{6}$ or $\mathrm{LiClO}_{4}$ in $\mathrm{PC}$, or $1 \mathrm{M}$ solution of $\mathrm{LiPF}_{6}$ in DMC, for $12 \mathrm{~h}$ followed by rapidly washing with THF to remove residual Li salts on the surface and drying under reduced pressure furnished $\mathrm{Li}^{+}$ion incorporated porous $\mathrm{CB}[6], \mathbf{3 a}, \mathbf{3 b}$, or $\mathbf{3 c}$, respectively, as a free-flowing, dry powder, which could be easily pressed into pellets without a binder (Fig. S5, ESI $\dagger$ ). The amount of $\mathrm{Li}^{+}$ions incorporated into the organic molecular porous solid was established by elemental analysis and inductively coupled plasma (ICP) analysis; $\mathbf{3 a}, \mathbf{3 b}$, and $3 \mathbf{c}$ have a molecular formula of $\mathrm{CB}[6] \cdot 0.8 \mathrm{LiPF}_{6} \cdot 3 \mathrm{PC}, \mathrm{CB}[6]$. $0.4 \mathrm{LiClO}_{4} \cdot 3.4 \mathrm{PC}$, and $\mathrm{CB}[6] \cdot 1.1 \mathrm{LiPF}_{6} \cdot 2.2 \mathrm{DMC}$, respectively. PXRD analysis indicated that the crystal structure of the framework was maintained after the impregnation process (Fig. S6, ESI $\dagger$ ). The presence of solvated $\mathrm{Li}^{+}$ions inside the channels of porous $\mathrm{CB}[6]$ crystals was further corroborated using FT-IR spectroscopy. In the FT-IR spectra of $\mathbf{3 a}$ and $\mathbf{3 b}$, a band associated with the $\mathrm{C}=\mathrm{O}$ stretching modes of coordinated PC appears at $1785 \mathrm{~cm}^{-1}$. The emergence of two new broad peaks at $843 \mathrm{~cm}^{-1}$ and $1088 \mathrm{~cm}^{-1}$ are attributed to the symmetric $\mathrm{P}-\mathrm{F}$ stretching modes of free $\mathrm{PF}_{6}{ }_{6}^{-}$ and the asymmetric stretching vibration modes of free $\mathrm{ClO}_{4}{ }^{-}$, respectively (Fig. S11, ESI $\dagger$ ). ${ }^{24-27}$

The $\mathrm{Li}^{+}$ion conductivity of $\mathbf{3 a}, \mathbf{3} \mathbf{b}$ and $\mathbf{3 c}$ was measured on pellets by ac impedance spectroscopy (Fig. 1). Regardless of the

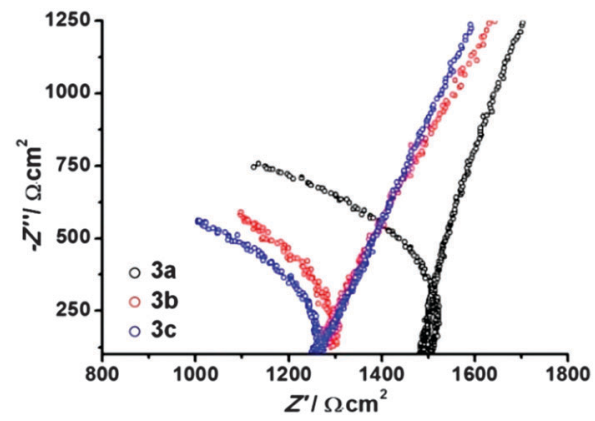

Fig. 1 Nyquist plots of the ac impedance data obtained for pellets of $3 a$, $3 \mathbf{b}$, and $3 \mathbf{c}$. $^{48}$

counter ions and solvents, they all exhibited similar conductivity values $\left(0.8-1.0 \times 10^{-4} \mathrm{~S} \mathrm{~cm}^{-1}\right)$ at room temperature (Table 1), which is almost four orders of magnitude higher than that of 2 $\left(<1.5 \times 10^{-8} \mathrm{~S} \mathrm{~cm}^{-1}\right)$ (Fig. S7, ESI $\dagger$ ), suggesting that facile migration of solvated $\mathrm{Li}^{+}$ions along the $1 \mathrm{D}$ channel of 2 is responsible for the high ionic conductivity values. ${ }^{14}$ These values are much higher than those of typical polyether-based polymer electrolytes $\left(\sim 10^{-8}-10^{-5} \mathrm{~S} \mathrm{~cm}^{-1}\right)^{28,29,32}$ and are comparable to the best values for MOF-based lithium solid electrolytes $\left(\sim 10^{-6}-10^{-4} \mathrm{~S} \mathrm{~cm}^{-1}\right) .^{14,15}$ Most importantly, the $\mathrm{Li}^{+}$ion conductivity of $\mathbf{3 a}, \mathbf{3 b}$ and $\mathbf{3 c}$ is just one order of magnitude lower than that of the desired battery electrolytes $\left(10^{-3} \mathrm{~S} \mathrm{~cm}^{-1}\right)$.

Temperature-dependent conductivity measurements of $\mathbf{3 a}$, 3b, and 3c revealed a typical Arrhenius-type activated behavior with activation energies in the range of $0.32-0.38 \mathrm{eV}$ (31-37 kJ mol${ }^{-1}$ ) (Fig. 2 and Table 1). These activation energy values are much lower than that of the well-established ceramic electrolyte LIPON-Li $\mathrm{PO}_{4}\left(0.55 \mathrm{eV}, 53.0 \mathrm{~kJ} \mathrm{~mol}^{-1}\right)^{30}$ and comparable to that observed in LISICON- $\mathrm{Li}_{14} \mathrm{ZnGe}_{4} \mathrm{O}_{16}(0.40 \mathrm{eV}$, $\left.38.5 \mathrm{~kJ} \mathrm{~mol}^{-1}\right){ }^{31}$ Furthermore, our materials showed 5 times lower activation energy compared to the $\mathrm{PEO} / \mathrm{Li}^{+}$polymer electrolyte $\left(1.66 \mathrm{eV}, 160.4 \mathrm{~kJ} \mathrm{~mol}^{-1}\right)$ and 2 times lower than that of the solid polymer electrolyte $\alpha$-CD ( $\alpha$-cyclodextrin)-PEO/ $\mathrm{Li}^{+}\left(0.78 \mathrm{eV}, 75.1 \mathrm{~kJ} \mathrm{~mol}^{-1}\right)$ made of PEO and the macrocyclic compound $\alpha-\mathrm{CD} .{ }^{32}$ With a high conductivity in the order of $10^{-4} \mathrm{~S} \mathrm{~cm}^{-1}$ and activation energy less than $0.4 \mathrm{eV}$, these $\mathrm{Li}^{+}$ ions incorporated into organic molecular porous solids can be classified as a superionic conductor. ${ }^{14}$ It is worth noting that the portals of each $\mathrm{CB}[6]$ are blocked by two neighboring $\mathrm{CB}[6]$ molecules in $2^{18}$ (and presumably in 3 as well), thereby preventing the direct interaction of $\mathrm{Li}^{+}$ions with the carbonyl oxygen atoms of $\mathrm{CB}[6]$. While a large shift $\left(\sim 15 \mathrm{~cm}^{-1}\right)$ in the $\mathrm{C}=\mathrm{O}$ stretching frequency was observed upon metal coordination to the carbonyl portals of $\mathrm{CB}[6],{ }^{32}$ almost no shift in the $\mathrm{C}=\mathrm{O}$ stretching frequency in $\mathbf{3 a}, \mathbf{3 b}$, and $\mathbf{3} \mathbf{c}$ compared to that in 2 (Fig. S11, ESI $\dagger$ ) is consistent with the lack of direct interactions between $\mathrm{Li}^{+}$ions and the carbonyl oxygen atoms of $\mathrm{CB}[6]$. Such an arrangement of $\mathrm{CB}[6]$ molecules in 3 may allow a relatively free movement of $\mathrm{Li}^{+}$ions in the 1D channels whereas in the case of polyether-based polymer electrolytes, the movement of the ions may be hindered by favorable charge-dipole interactions with the oxygen atoms of the polymer chains. ${ }^{33,34}$ 
Table 1 Lithium ion conductivity at RT, molar $\mathrm{Li}^{+}$concentration, molar conductivities, and activation energies of $\mathbf{3 a}$, $\mathbf{3 b}$, and $\mathbf{3 c}$

\begin{tabular}{|c|c|c|c|c|c|}
\hline Compounds & Electrolyte (per one CB[6]) & $\sigma\left(\times 10^{-4}\right) / \mathrm{S} \mathrm{cm}^{-1}$ & $C_{\mathrm{Li}}{ }^{+} / \mathrm{M}$ & $\Lambda_{\mathrm{M}}\left(\times 10^{-5}\right) / \mathrm{S} \mathrm{cm}^{-1} \mathrm{M}^{-1}$ & $E_{\mathrm{a}} / \mathrm{eV}$ \\
\hline $3 \mathbf{b}$ & $0.4 \mathrm{LiClO}_{4} \cdot 3.4 \mathrm{PC}$ & $0.8 \pm 0.4$ & 0.99 & $8 \pm 4$ & 0.32 \\
\hline $3 \mathbf{c}$ & $1.1 \mathrm{LiPF}_{6} \cdot 2.2 \mathrm{DMC}$ & $1.0 \pm 0.2$ & 1.2 & $8 \pm 2$ & 0.34 \\
\hline
\end{tabular}

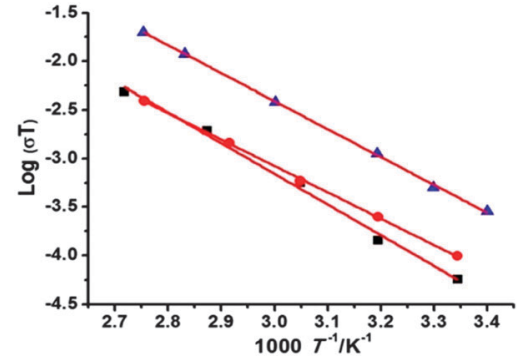

Fig. 2 Arrhenius plots of ionic conductivity data obtained from 3a $\mathbf{3 b}(\bullet)$, and $\mathbf{3 c}(\boldsymbol{\Lambda})$

One of the serious limitations of $\mathrm{Li}^{+}$electrolytes is the narrow operational temperature and limited electrochemical window. ${ }^{35}$ Although $\mathrm{LiPF}_{6}$ and $\mathrm{LiClO}_{4}$ show a good performance at low temperature and good compatibility using electrode current collectors $(\mathrm{Cu}$ and $\mathrm{Al})$, they are easily decomposed or deteriorated at $60-80{ }^{\circ} \mathrm{C}^{36}$ Thus, prevention of electrolyte deterioration and side reaction at high temperatures can increase the battery life. We thus decided to investigate the thermal stability and electrochemical stability of our materials. First of all, the crystal structures of $\mathbf{3 a}, \mathbf{3 b}$, and $\mathbf{3 c}$ were maintained at high temperatures up to $373 \mathrm{~K}$, as confirmed by PXRD (Fig. S10, ESI $\dagger$ ) and IR spectroscopy (Fig. S11, ESI $\dagger$ ), which suggests that they have a good thermal stability even above $80{ }^{\circ} \mathrm{C}$, a typical upper temperature window in liquid Li electrolytes and polymer electrolytes. ${ }^{37}$ We have also tested electrochemical stability of $\mathbf{3 a}, \mathbf{3 b}$, and $\mathbf{3 c}$ via cyclic voltammetry. Cyclic voltammograms were obtained between $+3 \mathrm{~V}$ and $+6 \mathrm{~V}$ for $3 \mathrm{a}$ and between $+2 \mathrm{~V}$ and $+5 \mathrm{~V}$ for 3b and $3 \mathbf{c}$ at room temperature and $373 \mathrm{~K}$ (Fig. S12, ESI $\dagger$ ). No electrolyte decomposition or electrochemical parasitic reaction in the operating voltage range was apparent as judged by a small current level across the sweeping voltages and no abrupt current increase was observed between 4 and $4.5 \mathrm{~V}$, which is known to be associated with electrolyte decomposition. ${ }^{1,38}$

Although DMC is widely used as a co-solvent in commercial Li electrolytes due to its low viscosity and high ionic conductivity, one of the shortcomings of the solvent is its high flammability and volatility. ${ }^{35}$ It thus prompted us to test the stability of $3 \mathrm{c}$ having a molecular formula of $\mathrm{CB}[6] \cdot 1.1 \mathrm{LiPF}_{6} \cdot 2.2 \mathrm{DMC}$ by measuring its ionic conductivity, while cycling the temperature between $298 \mathrm{~K}$ and $373 \mathrm{~K}$ (Fig. 3, and Fig. S9, ESI $\dagger$ ). Almost no change in conductivity was observed after each cycle for 4 days as shown in Fig. 3, which demonstrates a safe and high conducting behavior of $3 \mathbf{c}$ even at elevated temperatures. ${ }^{39,40}$

Having established that these $\mathrm{Li}^{+}$ion incorporated-organic molecular porous solids have excellent $\mathrm{Li}^{+}$ion conductivities, we measured the lithium transference number $\left(t_{\mathrm{Li}}{ }^{+}\right)$of the solid

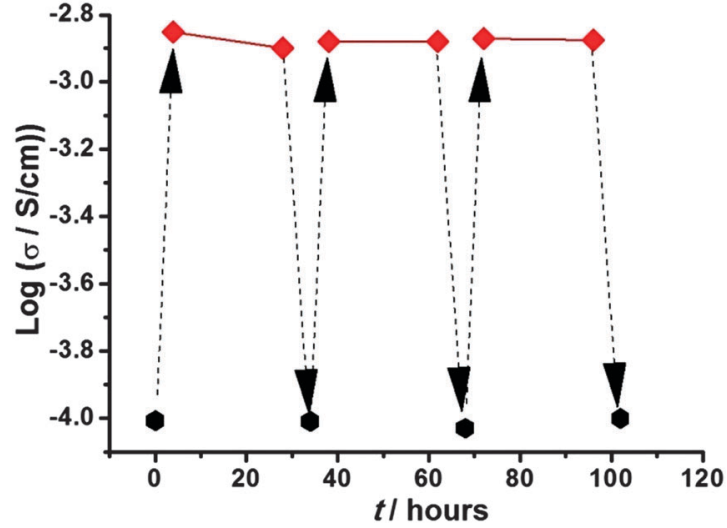

Fig. 3 Temperature cycling of $3 \mathrm{c}$ at elevated temperatures of up to $373 \mathrm{~K}$.

Table 2 Measured parameters for calculating transference number ${ }^{a}$

\begin{tabular}{llllll}
\hline Compounds & $R_{\mathrm{ss}} / \Omega$ & $R_{0} / \Omega$ & $I_{0} / \mu \mathrm{A}$ & $I_{\mathrm{ss}} / \mu \mathrm{A}$ & $t_{\mathrm{Li}}{ }^{+}$ \\
\hline 3a & 538 & 437 & 1.15 & 0.92 & 0.8 \\
3b & 569 & 433 & 127 & 91 & 0.7 \\
${ }^{a}$ Voltage bias $=$ & $0.5 \mathrm{~V}$. & & & & \\
\end{tabular}

electrolytes, another important parameter for battery applications, using the ac impedance method combined with the steady-state current technique. ${ }^{40,41}$ The measured $t_{\mathrm{Li}}{ }^{+}$values are 0.8 and 0.7 for $\mathbf{3 a}$ and $\mathbf{3 b}$, respectively, at room temperature (Fig. S13, ESI $\dagger$ ), which is in sharp contrast to the fact that those for conventional liquid electrolytes and $\mathrm{PEO} / \mathrm{Li}^{+}$polymer electrolyte are in the range of $0.2-0.5 .^{42-44}$ The high $t_{\mathrm{Li}}{ }^{+}$values observed for $\mathbf{3 a}$ and $\mathbf{3 b}$ (Table 2) suggest that the narrow $1 \mathrm{D}$ channels (pore diameter $7.5 \AA$ A; aperture $6 \AA$ ) in the molecular porous materials may hinder the movement of the bulky anions (2.4-2.6 ̊) while allowing a relatively fast movement of the small $\mathrm{Li}^{+}$ion $(0.76 \AA) .{ }^{45-47}$

In summary, we have developed a new type of solid lithiumion conducting materials prepared from an organic molecular porous solid made of cucurbit[6]uril. Most significantly, the incorporation of $\mathrm{Li}^{+}$ion into the 1D channels of guest-free porous $\mathrm{CB}[6]$ can lead to high $\mathrm{Li}^{+}$ion conductivity $\left(10^{-4} \mathrm{~S} \mathrm{~cm}^{-1}\right)$ and transference numbers $\left(t_{\mathrm{Li}}{ }^{+}=0.7-0.8\right)$. In addition, they showed an excellent performance in the temperature cycling test, confirming a stable ion conducting behavior even at elevated temperatures. To the best of our knowledge, this is the first example of highly thermally stable organic molecular porous material-based $\mathrm{Li}^{+}$ion conducting materials. The results described here represent significant progress in the designing and tailoring of a safe and high-performing solid electrolyte, which can address the existing challenges in 
lithium ion battery technologies and may provide new insight into the development of advanced lithium ion batteries.

We gratefully acknowledge the helpful discussion with other group members. We acknowledge the financial support from the Institute for Basic Science (IBS) [IBS-R007-D1].

\section{Notes and references}

1 G.-A. Nazri and G. Pistoia, Lithium Batteries: Science and Technology, Kluwer Academic, Boston, 2004.

2 M. S. Whittingham, Chem. Rev., 2004, 104, 4271.

3 P. Arora and Z. Zhang, Chem. Rev., 2004, 104, 4419.

4 J. B. Goodenough and Y. Kim, Chem. Mater., 2010, 22, 587-603.

5 J. M. Tarascon and M. Armand, Nature, 2001, 414, 359.

6 J. L. Schaefer, D. A. Yanga and L. A. Archer, Chem. Mater., 2013, 25, 834-839.

7 C. A. Angell, C. Liu and E. Sanchez, Nature, 1993, 362, 137-139.

8 F. Crose, G. B. Appetecchi, L. Persiand and B. Scrosati, Nature, 1998, 394, 456-458.

9 D. R. MacFarlane, J. Huang and M. Forsyth, Nature, 1999, 402, 792-794.

10 Z. Liu, W. Fu, E. A. Payzant, X. Yu, Z. Wu, N. J. Dudney, J. Kiggans, K. Hong, A. J. Rondinone and C. Liang, J. Am. Chem. Soc., 2013, 135, 975-978.

11 A. Morozan and F. Jaouen, Energy Environ. Sci., 2012, 5, 9269-9290.

12 L. E. Kreno, K. Leong, O. K. Farha, R. P. Van Duyne and J. T. Hupp, Chem. Rev., 2012, 112, 1105-1125.

13 T. Yamada, K. Otsubo, R. Makiura and H. Kitagawa, Chem. Soc. Rev., 2013, 42, 6655-6669.

14 B. M. Wiers, M.-L. Foo, N. P. Balsara and J. R. Long, J. Am. Chem. Soc., 2011, 133, 14522-14525.

15 R. Ameloot, M. Aubrey, B. M. Wiers, A. P. Gomora-Figueroa, S. N. Patal, N. P. Balsara and J. R. Long, Chem. - Eur. J., 2013, 19, 5533.

16 K. Nagata and T. Nanno, J. Power Sources, 2007, 174, 832-837.

17 K. Kim, N. Selvapalam, Y. H. Ko, K. M. Park, D. Kim and J. Kim, Chem. Soc. Rev., 2007, 36, 267-279.

18 S. Lim, H. Kim, N. Selvapalam, K. J. Kim, S. J. Cho, G. Seo and K. Kim, Angew. Chem., Int. Ed., 2008, 47, 3352.

19 H. Kim, Y. Kim, M. Yoon, S. Lim, S. M. Park, G. Seo and K. Kim, J. Am. Chem. Soc., 2010, 132, 12200.

20 M. Yoon, K. Suh, H. Kim, Y. Kim, N. Selvapalam and K. Kim, Angew. Chem., Int. Ed., 2011, 50, 7870-7873.

21 Y. Liang, C. Wang and C. Chen, J. Power Sources, 2007, 172, 886-892.

22 Q. Wang, P. Ping, X. Zhao, G. Chu, J. Sun and C. Chen, J. Power Sources, 2012, 208, 210-224.

23 Y. Wang, B. Li, J. Ji, A. Eyler and W. Zhong, Adv. Energy Mater., 2013, 3, 1557-1562.
24 M. Nie, D. P. Abraham, D. M. Seo, Y. Chen, A. Bose and B. L. Lucht, J. Phys. Chem. C, 2013, 117, 25381-25389.

25 R. Marom, O. Haik, D. Aurbach and I. C. Halalay, J. Electrochem. Soc., 2010, 157(8), A972-A983.

26 D. Battisti, G. A. Nazri, B. Klassen and R. Aroca, J. Phys. Chem., 1993, 97, 5826.

27 A. Schramm, C. Stroh, K. Dossel, M. Lukas, O. Fuhr, H. Lohneysen and M. Mayor, Chem. Commun., 2013, 49, 1076-1078.

28 F. B. Dias, L. Plomp and J. B. J. Veldhuis, J. Power Sources, 2000, 88, 169.

29 K. P. Barteau, M. Wolffs, N. A. Lynd, G. H. Fredrickson, E. J. Krammer and C. J. Hawker, Macromolecules, 2013, 46, 8988.

30 W. C. West, J. F. Whitacre and J. R. Lim, J. Power Sources, 2004, 126, 134-138.

31 L. Puech, C. Cantau, P. Vinatier, G. Toussanint and P. Stevens, J. Power Sources, 2012, 214, 330-336.

32 (a) F. F. da silva, C. A. F. de Oliveira, E. H. L. Falcao, J. Chojnacki, J. L. Neves and S. Alves Jr., Dalton Trans., 2014, 43, 5435-5442; (b) K. Chen, L.-L. Liang, H. Cong, X. Xiao, Y.-Q. Zhang, S.-F. Xue, Q.-J. Zhu and Z. Tao, CrystEngComm, 2012, 14, 3862-3864.

33 L. Yang, D. Wei, M. Xu, Y. Yao and Q. Chen, Angew. Chem., Int. Ed., 2014, 53, 1-6.

34 D. H. C. Wong, J. L. Thelen, Y. Fu, D. Devaux, A. A. Pandya, V. S. Battaglia, N. P. Balsara and J. M. De Simone, Proc. Natl. Acad. Sci. U. S. A., 2014, 111(9), 3327-3331.

35 D. Aurbach, Y. Talyosef, B. Markovsky, E. Markevich, E. Zinigrad, L. Asraf, J. S. Gnanaraj and H.-J. Kim, Electrochim. Acta, 2004, 50, 247-254.

36 S. T. Myung, Y. Sasaki, S. Sakurada, Y. K. Sun and H. Yoshiro, Electrochim. Acta, 2009, 55(1), 288-297.

37 M. Ogawa, K. Yoshida and K. Harada, SEI Technology Review, 2012, 74, 88-90.

38 P. P. Soo, B. Huang, Y. I. Jang, Y. M. Chiang, D. R. Sadoway and A. M. Mayes, J. Electrochem. Soc., 1999, 146(1), 32-37.

39 M. C. Smart, B. V. Ratnakumar, J. F. Whitacre, L. D. Whitcanack, K. B. Chin, M. D. Rodriguez, D. Zhao, S. G. Greenbaum and S. Surampudi, J. Electrochem. Soc., 2005, 152(6), A1096-A1104.

40 M. Song, Y. Kim, Y. B. Kim, B. Cho, B. N. Popov and H. Rhee, J. Electrochem. Soc., 2003, 150(4), A439-A444.

41 R. S. Kumar, M. Raja, M. A. Kulandainathan and A. M. Stephan, $R S C$ Adv., 2014, 4, 26171.

42 J. Zhao, L. Wang, X. He, C. Wan and C. Jiang, J. Electrochem. Soc., 2008, 155, A292-A296.

43 K. Xu, Chem. Rev., 2004, 104, 4303-4418.

44 C. S. Kim and S. M. Oh, Electrochim. Acta, 2000, 45, 2101-2109.

45 (a) L. C. Hardy and D. F. Shriver, J. Am. Chem. Soc., 1985, 107, 3823-3828; (b) M. Ue, A. Murakami and S. Nakamur, J. Electrochem. Soc., 2002, 149, A1385.

46 K. D. Kreuer, A. Wohlfarth, C. C. de Araujo, A. Fuchs and J. Maier, ChemPhysChem, 2011, 12, 2558-2560.

47 X. G. Sun and J. B. Kerr, Macromolecules, 2006, 39, 362-372.

48 Note that grain and grain boundary conduction within a pellet could not be distinguished from one semicircle in Nyquist plots. 